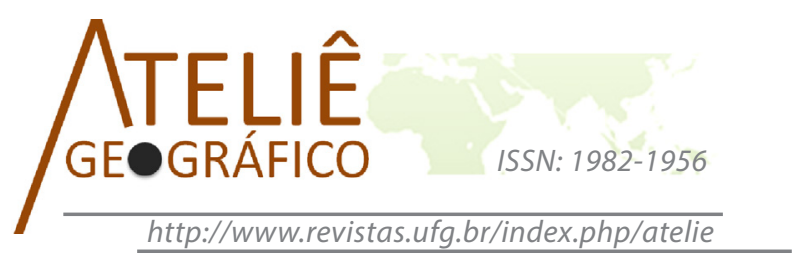

\title{
A mineração na região do Triângulo Mineiro/ Alto Paranaiba: agente de modernização e formação de fronteira
}

\author{
Mining as an agent of modernization and frontier \\ formation in Triângulo Mineiro/Alto Paranaíba region \\ L'exploitation minière dans la région du Triângulo \\ Mineiro/Alto Paranaíba: agent de modernisation et de \\ formation des frontières
}

\author{
Rita de Cassia Martins de Souza \\ Universidade Federal de Uberlândia \\ ritacmsou@gmail.com
}

\begin{abstract}
Resumo
A busca por minerais como o ouro e a prata ou as pedras preciosas foi um dos maiores empreendimentos desde a colonização no Brasil. Para além de se constituir simplesmente numa atividade econômica, a mineração gerou uma dinâmica intensa sobre o interior do território e por isso mesmo ela teve papel decisivo para a formação territorial brasileira. A área mais restrita a que diz respeito este trabalho, a região do Triângulo Mineiro/Alto Paranaíba, refere-se a uma parte do "grande interior" em que a mineração desempenhou e ainda desempenha funções de extrema importância tanto no sentido da geração de riquezas, como também para a própria constituição das sociedades locais e seus processos de formação. Desta forma, este trabalho vem contribuir para a compreensão da mineração enquanto um agente primordial para a formação territorial na área compreendida pela região administrativa do Triângulo Mineiro/Alto Paranaíba no Estado de Minas Gerais. Apresenta uma periodização para a mineração praticada na área procurando compreendê-la no processo mais amplo da formação territorial brasileira em seus momentos mais decisivos.

Palavras-chave: Mineração, Triângulo Mineiro/Alto Paranaíba, periodização,
\end{abstract} fronteira

\footnotetext{
Abstract

Besides being simply an economic activity, mining was generating an intense dynamic on the interior of the territory and, for this reason, it had a decisive role in Brazilian territorial formation. This study concerns about the Triângulo Mineiro/
} 
Alto Paranaiba area, usually referred as part of the "great interior" where the mining sector has played, and still plays, a role of utmost importance in terms of wealth generation, as well as in the constitution of the local societies and their processes of formation. Thus, this study intends to understand mining as an primordial agent for territorial formation in the area covered by the Triangulo Mineiro/Alto Paranaíba, an administrative region in the State of Minas Gerais. A periodization for mining practiced is in the area was presented, looking to understand it in the broader process of the Brazilian territorial formation, in their most decisive moments.

Keywords: Mining, Triângulo Mineiro/Alto Paranaíba, Periodization, Frontier

\begin{abstract}
Résumé
La recherche pour les minéraux comme 1'or, l'argent ou les pierres précieuses a été une des plus grandes entreprises depuis la colonisation du Brésil. En plus d'être simplement une activité économique, l'exploitation minérale a généré une dynamique intense sur le territoire et, pour cette raison, elle a joué un rôle décisif dans la formation territoriale Brésilienne. La région la plus restreinte concernant ce travail est la région du Triângulo Mineiro/Alto Paranaíba, qui concerne la partie du "grande interior", dans laquelle l'exploitation minière jouait et excerce encore des fonctions d'extrême importance, à la fois pour la génération de richesses, ainsi que pour la propre constitution des societés locales et leurs processus de formation. Ainsi, ce travail vient contribuer à la compréhension de l'exploitation minière en tant qu' agent primordial pour la formation territoriale dans la zone comprise dans la région administrative du Triângulo Mineiro / Alto Paranaíba, dans l'État de Minas Gerais. Une périodisation pour l'exploitation minière pratiquée dans la région a été présentée, afin de la comprendre dans le processus plus large de la formation territoriale brésilienne dans ses moments les plus décisifs.

Mots clés: Exploitation minière, Triângulo Mineiro/Alto Paranaíba, périodisation, frontière
\end{abstract}

\title{
Introdução
}

A mineração está entre as atividades econômicas mais importantes para a formação territorial brasileira. A busca por minerais como o ouro e a prata ou as pedras preciosas foi um dos maiores empreendimentos em que os colonizadores se envolveram durante os primeiros séculos, porém sem grande sucesso. Não encontrando os minerais preciosos, tal e qual os espanhóis na costa do Pacífico, os portugueses mantiveram-se na costa atlântica "como caranguejos"1 por longos anos dedicando-se à exploração extrativa e agrícola. O desejo dos metais e pedras preciosos permaneceu importante até o século XVIII quando efetivamente os bandeirantes paulistas alcançaram o intuito desde o início almejado.

Para além de se constituir simplesmente numa atividade econômica, as atividades mineradoras geraram uma dinâmica intensa sobre o interior do território anexando, inclusive, terras além do Tratado de Tordesilhas. Não há como descartar desta análise a expansão urbana sofrida a partir da descoberta de jazidas de metais e pedras preciosas. Essas descobertas no interior geraram a instalação de inúmeras vilas e aldeias em torno das áreas de exploração e ao longo das vias de acesso a essas áreas.

Desde então, a zona central do que veio a se constituir como o Estado de Minas Gerais até as fronteiras com os atuais países da América do Sul, ou o que pode ser 
chamado de "grande interior" ou "grande sertão" tem se constituído no grande desafio do Estado brasileiro.

A mineração cumpre papel decisivo e inescapável da formação desse imenso território. A área mais restrita a que diz respeito este trabalho refere-se a uma parte desse "grande interior" em que a mineração desempenhou e ainda desempenha funções de extrema importância tanto no sentido da geração de riquezas, como também para a própria constituição das sociedades locais e seus processos de formação.

Este trabalho tem como objetivo contribuir para a compreensão da mineração enquanto um agente primordial de modernização e de formação de fronteira na área compreendida pela região administrativa do Triângulo Mineiro/Alto Paranaíba no Estado de Minas Gerais. Apresenta-se uma periodização para a mineração praticada na área procurando compreendê-la no processo mais amplo da formação territorial brasileira em seus momentos mais decisivos.

\section{A mineração no Triângulo Mineiro/Alto Paranaíba: particularidades}

Em primeiro lugar deve-se destacar que a mineração praticada na região do Triângulo Mineiro/Alto Paranaíba (Figura 1) apresenta dinâmica e tipologia muito distinta da apresentada na porção leste do Estado de Minas Gerais. Isto tem implicações bastante profundas sobre toda a realidade das duas áreas em foco, ou seja, são diferentes

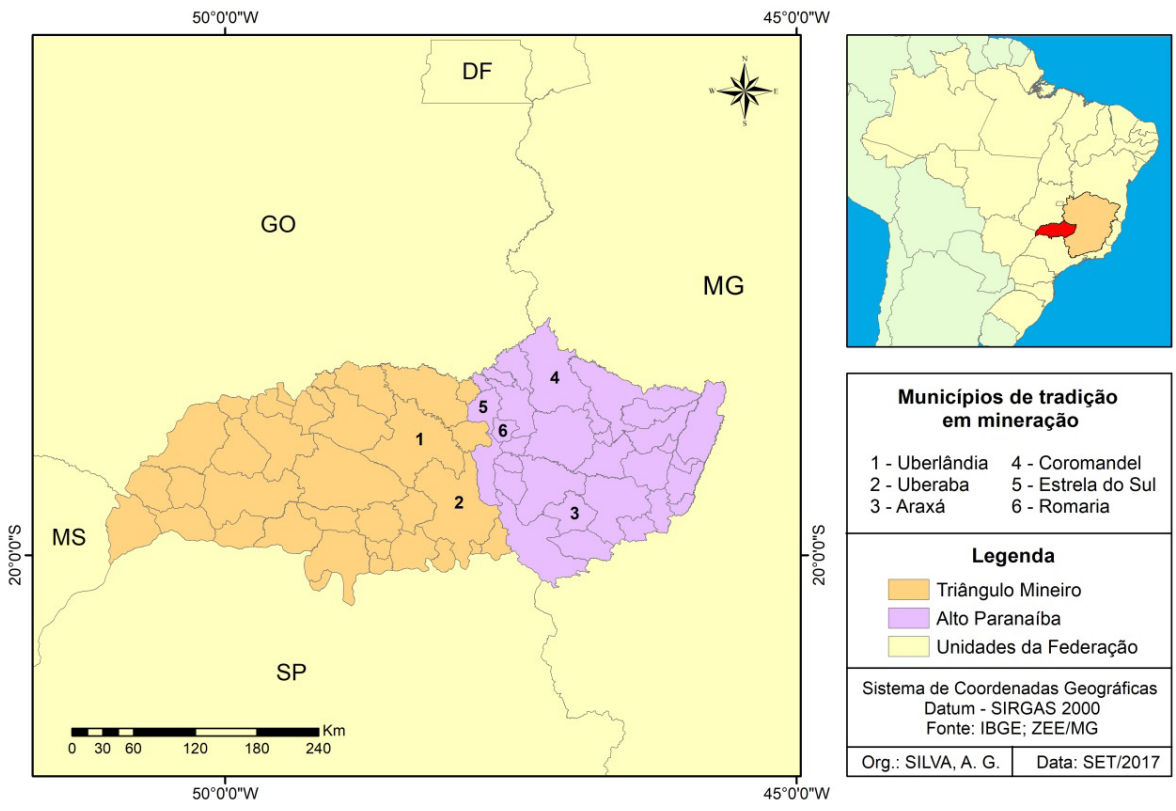

Figura 1. Triângulo Mineiro/Alto Paranaíba. Localização e municípios de tradição em mineração 
dinâmicas com consequências sobre a formação territorial das duas áreas. O Triângulo Mineiro na origem de sua ocupação foi uma região de suporte à atual Zona da Mata Mineira e às minas de Goiás, sendo área de passagem de gado e de tropeiros.

Segundo Lourenço (2005) existia na região do atual Triângulo Mineiro/Alto Paranaíba, dois grandes fluxos de passagem em 1748, a Estrada do Anhanguera que ligava São Paulo as minas de Goiás (Estrada dos Goyazes) e outro que ligava as minas de Goiás a São João Del Rei e Vila Rica, passando pelas minas de ouro de Paracatu.

Portanto, fica evidente que a formação da região, desde o início, esteve ligada à produção minerária principalmente com a função de caminho de passagem. Entretanto, não são de pouca importância as jazidas de ouro e diamantes descobertas na região. Em 1760 a descoberta de ouro em Desemboque transformou esse vilarejo em um dos principais arraiais da área. $\mathrm{O}$ arraial de Desemboque ficou muito conhecido também por ser caminho alternativo à cobrança do quinto e das derramas, ou seja, dos impostos cobrados pela Coroa portuguesa sobre os metais e pedras preciosos explorados na Colônia (LOURENÇO, 2005).

$\mathrm{O}$ esgotamento das técnicas de exploração do ouro, na segunda metade do século XVIII, impulsionou uma nova forma de ocupação nas fronteiras, com fluxo migratório tanto para o Sul quanto para Oeste das minas da porção leste de Minas Gerais. Essa ocupação na qual se insere a região aqui tratada foi caracterizada por dois tipos de povoamento, um ligado à mineração e outro ligado à pecuária.

A descontinuidade de povoamento era uma marca forte nas áreas ligadas à mineração, pois estas dependiam do favorecimento dos fatores geológicos. Ao contrário, as áreas ligadas à agropecuária apresentavam povoamento contiguo, ou seja, os núcleos urbanos eram irradiados, mantendo continuidade entre os mesmos. As ocupações motivadas pela agropecuária fomentavam a criação de vetores irradiados, isto é, às margens dos caminhos principais, e que levavam ao aparecimento de novas povoações. Os fazendeiros dependiam desses caminhos para ter acesso às mercadorias vindas dos núcleos urbanos do leste e do sul e também para comercializar o gado.

Sobre os núcleos mineradores presentes no oeste mineiro, Lourenço (2005) afirma que:

Há outra diferença, no padrão espacial de ocupação, que pudemos perceber no caso do Oeste Mineiro. A localização dos núcleos mineradores é que conformou o traçado das vias, e não o contrário. Parece lógico que, à medida que se faziam as descobertas auríferas, e que em torno delas se desenvolviam os arraiais do ouro, o intenso fluxo de mercadorias e pessoas fazia surgir os caminhos, ligando-os aos núcleos primazes ou de exportação. (Lourenço, 2005, p.113)

A partir de 1852, houve um intenso movimento migratório para a região com a descoberta do Diamante Estrela do Sul nas margens do Rio Bagagem, fazendo da área um importante núcleo minerador. Conforme aborda Lourenço (2007),

Bagagem, centro minerador desde 1818, experimentou intenso surto de crescimento depois de 1852, com a notícia da descoberta do diamante Estrela 
do Sul e a consequente migração de garimpeiros. Em 1867, com a descoberta de diamantes também a montante do Rio Bagagem, houve grande ocupação no termo de Água Suja (LOURENÇO, 2007, p.135).

Tem-se, portanto, os elementos básicos suficientes para atestar a particularidade da formação territorial na região do Triângulo Mineiro. O histórico específico de ocupação gerado pela mineração e pela agropecuária, per se justificaria o esforço da compreensão desse processo que, em geral, na literatura científica, é relegado a um tratamento generalizado enquanto "a mineração em Minas Gerais”. Além da recuperação do histórico da ocupação tão fortemente ligado à mineração, cabe proceder ao resgate dos processos contemporâneos em que a atividade mineradora continua exercendo função e papel decisivos na formação territorial da região.

\section{Uma periodização para a mineração na região do Triângulo Mineiro/Alto Paranaíba}

A periodização para a região do Triângulo Mineiro/Alto Paranaíba com foco na mineração, conforme aqui se propõe, precisa ser enquadrada na lógica da ocupação do "grande interior", mais especificamente na área central do território brasileiro. Essa delimitação se faz necessária, pois ao longo da história ocorreram vários processos que levaram essa região a se configurar em um novo espaço tecnificado dentro do território nacional. Trata-se de uma proposta sustentada em períodos longos (Braudel, 1992) de modo a compreender o processo de inserção da área, em particular, e do Brasil na economia mundo (Wallerstein, 1979).

\section{A ocupação do interior do território e o papel da mineração}

Becker e Egler (1998) propõem periodização interessante para se compreender a formação territorial brasileira, em que se apresentam diferentes fases de incorporação do país na economia-mundo, seguindo três padrões: o da colônia, o do império mercantil e o de capitalismo industrial periférico.

Estes três padrões se estendem desde os primeiros assentamentos portugueses até a formação do Estado moderno e a industrialização. Só no final dos anos 1960, o Brasil emergiu como semiperiferia na economia-mundo, transformando-se numa potência regional na América do Sul. (BECKER \& EGLER, 1998, p. 37).

$\mathrm{O}$ extenso território brasileiro que veio a se constituir como Estado nacional independente, em 1822, é marcado por diferentes "histórias regionais" em vista, primeiramente, das dificuldades de comunicação e integração entre as diversas áreas que iam sendo ocupadas. Um dos maiores desafios para o poder central, inicialmente a Coroa portuguesa e, com a Independência, o Governo propriamente brasileiro, foi justamente promover a unidade desse imenso território constituído por brutais diferenças regionais. A noção de "arquipélago econômico" representa um esforço no sentido de apresentar essa configuração das economias regionais que, em verdade, constituíam-se em "regiões independentes", em termos de sua estrutura sócioeconômica, cultural e mesmo política, em sentido lato. 
No longo processo de formação da unidade nacional, considerando-se desde o período colonial, há de se considerar ainda que, fora das regiões em que de fato se configuravam as economias regionais com suas dinâmicas próprias, havia ainda imensos espaços tidos como "vazios demográficos", ou seja, áreas "livres" em que a colonização ou a ocupação não os havia atingido. Embora os limites do Estado brasileiro já estivessem praticamente todos demarcados por ocasião da independência, a maioria absoluta do território encontrava-se na condição desse "vazio".

Esta ideia tem muita força na construção do ideário sobre o país de modo que a imensidão de terras foi sempre vista como "áreas a serem ocupadas e desbravadas". Os povos ameríndios a princípio e depois os fugidos (a maioria deles negros escravos) e a organização sócio-econômica que lhes dizia respeito sempre foi sistematicamente olvidada em favor de discursos que pregavam a abundância da natureza a ser explorada e a ignorância e o atraso civilizatório desses povos.

Moraes (2002) define essas áreas como "fundos territoriais", de certo modo, procura-se, aqui, entendê-las como regiões dentro do território ainda não exploradas do ponto de vista do capital. Para este autor, a formação brasileira foi condicionada à conquista espacial e a manter os fundos territoriais; interesse esse marcante no pensamento das elites nacionais. Pelo menos do final do século XIX até a década de 1930, o interesse na consolidação do poder das oligarquias era o de fomentar a unificação nacional através de um poder descentralizador que garantisse os interesses regionais.

A ocupação do "grande sertão" deu-se sustentada num discurso em que se destaca a intenção de levar a civilização para o interior: prevalece a ideia da "barbárie" do interior. Segundo Moraes:

a ideia de levar as luzes para o interior longínquo acaba por conformar uma mentalidade que a natureza e os meios naturais originais são associados à situação de barbarismo e atraso, ao passo que a devastação do quadro natural é entendida como progresso. (MORAES, 2002, p.119)

Entre o final do século XIX e o início do XX (1870 e 1930), os discursos sobre a necessidade da civilização, marcantes na sociedade escravagista que se sustenta até a Abolição da Escravatura em 1888, são transmudados em uma nova forma de ver o problema: passa-se cada vez mais fortemente a se falar em inserção na modernidade, conforme já apontado por Moraes:

[a modernização) conceito central do pensamento brasileiro do século XX, reveste-se também de densa espacialidade. Pode-se dizer que modernizar é entre outras coisas, reorganizar e ocupar o território, dotá-lo de novos equipamentos e sistemas de engenharia, conectar suas partes com estradas e sistemas de comunicação. Enfim, modernização implicava no caso brasileiro necessariamente valorização do espaço. Nesse sentido, o país podia ser novamente equacionado no âmbito espacial no qual o Estado devia agir para instalar o novo projeto nacional: a construção do Brasil moderno. (MORAES, 2002, p. 121) 
Dentro dos princípios modernizantes vigentes, sobretudo após os anos de 1930, era necessária a transformação do Brasil rural em um país urbano industrial, e em que as atividades econômicas, de modo geral, fossem organizadas de modo a responder às demandas industriais. Esse processo fomentou o êxodo rural, a modernização da agricultura, a criação de sistemas que interligavam todo o espaço, através de planos de Estado para a integração nacional. Nesse sentido, cabe destacar o modelo autoritário adotado pelo Estado brasileiro, entendido por diferentes grupos nacionais, como o único agente capaz de dar a ordem necessária a um país composto por uma "massa informe" e por uma "elite despreparada" para a tarefa de alçá-lo à condição de um Estado importante entre as nações ricas e potências mundiais (Anselmo, 2002).

O esforço pelo estabelecimento da unidade encontrou nos anos de 1930, segundo Francisco de Oliveira (1981), seu ponto crucial, quando a partir do processo de industrialização instalado passa-se a formar o mercado interno brasileiro, principal e decisivo agente de integração de todas as regiões do país. A partir desse ponto pode-se começar a falar que a grande diversidade presente passa a ser coordenada no sentido da construção de uma unidade efetiva.

\section{A economia regional mineira: do auge às políticas de recuperação}

Tendo em vista os complexos regionais no âmbito nacional, há ainda que se estacar que internamente às áreas de funcionamento dessas economias há igualmente diversificações internas que nos obrigam a refletir sobre a coesão e os fatores que a movem na escala de cada uma dessas economias regionais. Afirma-se que a exploração minerária em Minas Gerais foi o primeiro e verdadeiro impulso para a integração entre diferentes economias regionais no Brasil: as províncias do sul, São Paulo e a zona de exploração mineira. Antes que passemos a analisar propriamente a inserção do Triângulo Mineiro no conjunto da ocupação do território nacional é melhor entender minimamente a inserção em Minas Gerais.

Godoy (2009) propõe que Minas Gerais atravessou algumas fases importantes em seu desenvolvimento que devem ser levadas em consideração. A primeira diz respeito a um momento em que vigorou a economia do ouro, balizada no mercado externo e no trabalho escravo:

O primeiro momento é a "economia do ouro", que compreende aproximadamente as três primeiras quadras do século XVIII e tem como características fundamentais um dinâmico sistema escravista centrado na mineração, orientado para o mercado externo, pois, em última instância, trata-se de um produto colonial e uma "polarização espacial" exercida exclusivamente pelo núcleo minerador, pelos espaços da mineração, concentrados aproximadamente no centro geográfico da capitania. No século XVIII, Minas Gerais constituise no principal pólo do mercado interno da Colônia. É com a formação e desenvolvimento da "economia do ouro" que conhecemos o primeiro movimento de integração das economias regionais da América portuguesa. (GODOY, 2009, p. ) 
Essa fase claramente só se configurou com a ocupação do interior da colônia e, se no princípio, era uma ação de cunho privado, assim que começou a render frutos, foi encabeçada pelo estado português.

No final do século XVIII, quando a atividade começou a experimentar as primeiras dificuldades, iniciou-se um novo surto de expansão para o interior marcando o alargamento da fronteira na direção oeste. Nessa fase, segundo Godoy (2009) teve início a primeira transição do sistema produtivo na área.

Uma reestruturação produtiva, que significa o alargamento da fronteira de ocupação; a aceleração de um processo em curso, desde meados do século XVIII, de diferenciação espacial; e a conversão de um movimento centrípeto, predominante até a terceira quadra do século XVIII, de procura pelo centro de Minas Gerais, pelos espaços da mineração, em um movimento centrífugo, de procura pela fronteira, de alargamento da fronteira. Nesse quadro, há uma redefinição do padrão integrativo de Minas Gerais com as outras economias regionais do Brasil. (GODOY, 2009, p.93-94)

Este mesmo autor sinaliza que a conclusão dessa transição desemboca justamente numa fase em que o antigo sistema escravista ligado ao mercado externo volta-se, a partir da crise experimentada no sistema minerário, para o mercado interno e que, justamente, essa dinâmica está no cerne da diferenciação do estado de Minas Gerais. Segundo o autor "O núcleo dinâmico desse sistema escravista são as atividades da agropecuária e os setores de transformação associados ou não à agropecuária. Vigora forte descentralização econômica, ou a constituição de sistemas econômicos sub-regionais com maior ou menor grau de autonomia”. (GODOY, 2009, p.92)

Uma segunda transição na economia regional de Minas Gerais ocorreu na passagem do século XIX para o XX quando então, segundo Godoy (2009), apresentase a grande "possibilidade histórica" para as elites mineiras recuperarem a condição de fausto do início do século XVIII. As condições externas que se aliam às condições internas do Estado brasileiro à época são decisivas para compreender o momento. A instalação da República e o fim do período imperial fazem parte desse contexto em que a modernização passará a ser o mote do ideário político e intelectual do Brasil. Para um autor como Moraes (2000) trata-se da passagem de um discurso que da defesa da civilização contra a barbárie passa à defesa da modernidade contra o atraso.

Ou seja, desde por volta de 1850, estão em movimento uma série de transformações econômicas, políticas, sociais, culturais e institucionais que, no longo prazo, irão alterar profundamente o perfil do Brasil. Destacam-se quatro processos que integram nossa modernização. A transição do trabalho escravo para o trabalho livre é o primeiro. O segundo é o estabelecimento da propriedade privada juridicamente plena, a partir de 1850, com a Lei de Terras. O terceiro processo é a modernização das relações comerciais e financeiras, particularmente a progressiva constituição de sistema bancário. O quarto é a transição de rede de transportes tradicionais para um sistema de transportes moderno e integrado. É preciso salientar: são processos de longo prazo, portanto se estendem por um intervalo de tempo largo e, no caso de países 
periféricos, em especial os países de tradição colonial, são processos marcados pela incompletude e ritmo relativamente lento (GODOY, 2009, p.93-94)

$\mathrm{O}$ não enfrentamento das debilidades regionais perante o processo de modernização que se instalava gerou a própria percepção do atraso econômico de Minas Gerais e, a partir de então, passa-se a promover uma série de iniciativas que visam recuperar a região de seu atraso relativo perante outras áreas que se movimentaram no sentido do aproveitamento das oportunidades colocadas pelo sistema e pelo contexto mundial, como São Paulo por exemplo.

A constatação do atraso econômico estimulará o desenvolvimento de planos para a superação dessa condição, portanto uma articulação política por meio da concepção e efetivação de projetos para o desenvolvimento regional de Minas Gerais. A referida consciência somente emerge no início do século XX porque a primeira década republicana é marcada pela resolução de uma série de conflitos internos as elites mineiras, ainda incapazes de se pensarem pertencendo a uma entidade regional comum. Trata-se de tardia percepção da condição de subdesenvolvimento resultante da perda da mencionada "oportunidade histórica". Então, a partir desse ponto, o que se irá verificar, pelo menos até o período que trataremos - a década de 60 -, é a colocação em movimento de uma série de projetos de desenvolvimento regional com vistas a superar a posição de atraso relativo. (GODOY, 2009, p.100)

\section{As grandes etapas da exploração minerária no Triângulo Mineiro/Alto Paranaíba}

Se de um lado torna-se imprescindível proceder à análise da mineração no Triângulo Mineiro/Alto Paranaíba à luz do contexto geral do desenvolvimento da atividade no estado de Minas Gerais, por outro não é de somenos importância desde o princípio chamar a atenção para a particularidade da região diante do conjunto do estado.

Em vista disso, nossa primeira preocupação é entender que a área encontrase na confluência estratégica entre três complexos regionais decisivos para a formação econômica brasileira: as Minas da Zona da Mata e Central, São Paulo e o Planalto Central brasileiro.

A região da exploração mineira par excellence que configurou a economia regional mineira ainda no período colonial e que, segundo Godoy (2009), girava totalmente em torno de grandes centros urbanos regionais como Ouro Preto ou Belo Horizonte está muito bem alicerçada na Zona da Mata e Zona Central do estado de Minas Gerais. No conjunto do grande "mosaico mineiro" que é como o estado acaba se estruturando mesmo na contemporaneidade, as duas regiões administrativas mencionadas ainda hoje têm seu desenvolvimento muito marcado pelo passado minerador.

Não é de somenos importância também destacar que o estado de Minas Gerais é por demais marcado pelas suas diferenciações internas. A proposição do Mosaico Mineiro encontrada em Wirth (1982), Dulci (1999) e outros estudiosos, reproduz o "costume" (Wirth, 1982), ou seja, o modo como a própria comunidade percebia ou percebe as particularidades do estado mineiro. Segundo Wirth (1982) é mesmo uma pena que nenhuma das divisões oficiais tenha respeitado tal proposição. 
Infelizmente, não existe uma definição das zonas que seja de modo geral aceita e que os historiadores possam usar. Os geógrafos brasileiros recentemente especificaram 17 sub-regiões fisiográficas que se ajustam a seus propósitos; aparecem na maioria dos mapas e relatórios, mas seu esquema não é muito útil para o traçado das tendências históricas... Por causa disso decidi manter as sete zonas tradicionais, que refletem padrões diferentes de colonização, assim como mudanças sociais, econômicas e políticas, melhor do que qualquer outra divisão. O mapa [Fig.1] as fronteiras zonais aproximadas, que foram sancionadas pelo costume. Essa divisão em sete unidades foi usada em todo o livro. (WIRTH, 1982, p.41)

Dulci (1999) também aproveita a proposição do Mosaico Mineiro, mas recorre à elaboração de Diegues para completar a idéia. As regiões culturais do estudo mais antigo de Diegues (1960) tem um cunho mais de tipo culturalista recorrendo a várias elaborações teóricas entre as quais pode-se citar Max Sorre, Gilberto Freire, Franz Boas, Preston James, entre outros. As regiões culturais em Diegues, no entanto, referem-se a um "conjunto de sugestões... baseadas num critério que me parece o mais adequado, e menos limitativo, para a caracterização de regiões culturais no Brasil" (Diegues, 1960 , p.3), ou seja, o propósito do autor é elaborar uma proposta capaz de dar conta da compreensão do Brasil como um todo.

A divisão das regiões mineiras que aparece em Dulci (1999) por isso, ainda que remeta ao Mosaico Mineiro não se limita ao costume, mas vai buscar numa proposição de cunho científico seu embasamento. Nenhum dos autores mencionados nega a força das atividades econômicas na configuração das regiões de Minas de Gerais e menos ainda, como se era de esperar, a força política. Trata-se de desenvolver uma estratégia de compreensão que se sustente na base material e simbólica, que permita apreender a dinâmica do estado de Minas Gerais, o que é, sem dúvida, um grande desafio, dadas as diversidades naturais, sociais, culturais e econômicas desse particular estado da federação brasileira.

Neste trabalho apresentamos uma periodização para o desenvolvimento da atividade mineraria na região do Triângulo Mineiro/Alto Paranaíba que procura contemplar a dinâmica do desenvolvimento da região na formação sócio espacial brasileira em primeira instância e enquadrá-la nas particularidades do desenvolvimento do estado de Minas Gerais em segunda instância.

Assim, podemos pensar em quatro grandes fases em que a mineração se desenvolve tendo uma exploração particular como predominante, porém as atividades antigas não deixam de existir nas fases subseqüentes. Cada uma dessas fases revela, em verdade, o desenvolvimento maior do Brasil e de Minas Gerais, daí a importância de toda discussão precedente realizada neste trabalho.

A primeira fase acontece com a exploração do ouro e do diamante e se dá paralelamente às descobertas auríferas em Goyaz (atual estado de Goiás). São destaques nessa época a descoberta de diamantes em Estrela do Sul ou na antiga Vila de Água Suja, atual cidade de Romaria. Essa fase teve seu auge no século XIX, mas a exploração de ouro e diamante se estende até os dias atuais com as maiores explorações sendo verificadas nas cidades de Paracatu e Coromandel. 
A segunda fase é marcada pelo início da exploração com muita intensidade de minerais como: o basalto, calcário areias e argilas, que serviram como matéria prima para a construção civil. O evento mais importante que desencadeia essas explorações é a construção de Brasília, a capital do Brasil inaugurada em 1960. A estratégia de deslocar a capital do Rio de Janeiro para o Planalto Central brasileiro desencadeou um intenso processo de urbanização com a formação de extensa rede de cidades. A exploração desses minerais até os dias de hoje ainda se dá de maneira muitas vezes irregular e clandestina.

$\mathrm{Na}$ terceira fase a mineração foi fundamental para o fornecimento de minerais essenciais para a elaboração de insumos agrícolas necessários à correção e fertilização dos solos do cerrado com minerais fosfatados. O início dessas explorações se deu nos anos de 1960, porém essa é uma das atividades minerarias mais importantes na região até hoje acompanhando o próprio desenvolvimento do agronegócio. A área se destaca dentro do Mosaico Mineiro como produtor agrícola moderno, muito ligada ao mercado paulista. É pela região também que é escoada a produção agrícola, essencialmente voltada para o mercado externo, provinda da região Centro Oeste.

A quarta fase tem início praticamente concomitante à anterior e é marcada pela exploração de minerais de cunho estratégico como o nióbio. Seu auge é atingido nos anos de 2000 com a exploração realizada na cidade de Araxá e estendendo-se até os dias atuais.

\section{Considerações finais}

As regiões do Triângulo Mineiro e Alto Paranaíba, ao longo do tempo, vêm sendo valorizadas incessantemente através dos processos minerários, acompanhando demandas que se colocam a partir dela própria e de demandas que se constituem externamente.

$\mathrm{O}$ que se pode concluir é que a mineração apresenta-se ao longo de toda a história da área, desde a entrada dos bandeirantes no século XVIII, é que a mineração sempre se constituiu como uma importante atividade econômica. Entretanto, o seu valor histórico maior pode ser visto pelo significado geoestratégico. No início foi fundamental enquanto agente de expansão do território, demarcando novas fronteiras de ocupação; ao mesmo tempo foi se estabelecendo como agente decisivo da urbanização na área; posteriormente com as iniciativas de construção da capital no Planalto Central, serviu de agente fundamental no fornecimento das matérias primas, indispensáveis ao grande processo de construção das novas cidades; ainda no ímpeto desbravador que permeou a ocupação do grande interior, ofereceu as matérias primas indispensáveis à correção dos solos do cerrado; mais recentemente passou a abrigar a produção de nióbio, mineral estratégico fundamental para as novas tecnologias contemporâneas. De modo que se pode concluir que a mineração no Triângulo Mineiro/Alto Paranaíba apresenta um importante papel de agente modernizador ou, portanto, de ressignificação da fronteira numa região que é desde as origens de sua ocupação uma área de conexão entre pelo menos três grandes complexos regionais no Brasil.

Cabe (re)conhecer o "mapa da mina" distinguindo o papel que a mineração teve, tem e terá para as regiões tratadas neste trabalho não simplesmente por suas funções 
econômicas, propriamente ditas, mas enquanto agente estruturador geoestratégico do território.

\section{Agradecimentos}

Agradeço à FAPEMIG através do Projeto FAPEMIG/Conseil Régional NPDC - APQ03544-15, "Wealth Through Sharing - Riquezas Compartilhadas".

\section{Referências}

WALLERSTEIN, I. El modierno sistema mundial: la agricultura capitalista y los origins de la economía-mundo europea en el siglo XVI. México: Siglo Veintiuno, 1979. v. 1.

BRAUDEL, F. História e ciências sociais: a longa duração. In: BRAUDEL, F. Escritos sobre a história. São Paulo: Perspectiva, 1992. (Publicado originalmente in Annales E. S. C., n. 4, 1958).

ANSELMO, Rita de Cássia Martins de Souza. A formação do professor de Geografia e o contexto da formação nacional brasileira. In. Pontuschka, N.N.; Oliveira, A.U. Geografia em perspectiva: ensino e pesquisa. São Paulo: Ed. Contexto, 2002.

BECKER, B. K.;EGLER, C. A. G. Brasil: uma nova potência regional na economia mundo. Ed. 3, Bertrand, Rio de Janeiro 1998.

LOURENÇO, L.A. B. A Oeste das Minas. Escravos, índios e homens livres numa fronteira oitocentista, Triângulo Mineiro (1750-1861), 2005, Edufu, Uberlândia, 353 p.

LOURENÇO, L.A. B. Das fronteiras do Império ao coração da República: o território

do Triângulo Mineiro na transição para a formação sócio-espacial capitalista na segunda metade do século XIX. 2007, 306 f. Tese de Doutoramento, F.F.L.C.H., USP, São Paulo 2007.

MORAES, A. C. R. Território e História no Brasil. 3 ed., São Paulo: Annablume, 2002.

MORAES, A.C.R. Bases da formação territorial do Brasil. O longo século XVI. São Paulo: Hucitec, 2000.

OLIVEIRA, Francisco. Elegia para uma re(li)gião. Sudene, Nordeste, Planejamento e conflitos de classe. Rio de Janeiro, Paz e terra, 1981.

GODOY, M. M. Minas Gerais na República: atraso econômico, Estado e planejamento. Cad. Esc. Legisl., Belo Horizonte, v. 11, n. 16, p. 89-116, jan./jun. 2009.

Wirth, J. D. O fiel e a balança: Minas Gerais na Federação Brasileira. 1889-1937. Rio de Janeiro: Paz e Terra, 1982.

DULCI, O. S. Política e recuperação econômica em Minas Gerais. Belo Horizonte: Ed. UFMG, 1999.

DIEGUES Jr, Manuel. Regiões culturais do Brasil. Rio de Janeiro: Centro Brasileiro de Pesquisas Educacionais, 1960. 
Rita de Cassia Martins de Souza

Possui doutorado em Geografia pela Universidade Estadual Paulista Júlio de Mesquita Filho - UNESP. Atualmente é Professora da Universidade Federal de Uberlândia nos cursos de graduação e pós-graduação em Geografia.

Endereço: Instituto de Geografia - UFU. Campus Santa Mônica - Bloco 1H. Av. João Naves de Ávila, 2121 - Bairro Santa Mônica. Uberlândia - MG - CEP 38400-902.

E-mail: ritacmsou@gmail.com

Recebido para publicação em março de 2017 Aprovado para publicação em maio de 2017 